REVIEW

\title{
Getting the most out of cardiac rehabilitation: a review of referral and adherence predictors
}

\author{
L Jackson, J Leclerc, Y Erskine, W Linden
}

Comprehensive cardiac rehabilitation reduces mortality and morbidity but is utilised by only a fraction of eligible cardiac patients, with the participation rate of women being only about half that of men. This quantitative review assesses 32 studies meeting inclusion criteria, describing 16804 patients, 5882 of whom were female. It was found that the main predictor of referral to a cardiac rehabilitation programme was the physician's endorsement of the effectiveness of such a programme. Patients were more likely to participate in rehabilitation programmes when they were actively referred, educated, married, possessed high self efficacy, and when the programmes were easily accessible. Patients were less likely to participate when they had to travel long distances to participate in a cardiac rehabilitation programme, or experienced guilt over family obligations. Women were less often referred and participated less often even after referral. In conclusion, many of the observed predictors, including those particular to women, are potentially modifiable with the help of health professionals.

See end of article for authors' affiliations

Correspondence to: Professor W Linden Behavioural Cardiology Laboratory, Psychology/ UBC, 2136 West Mall, Vancouver BC, Canada V6T 1Z4; wlinden@psych. ubc.ca

Accepted

10 September 2004

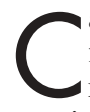
ardiovascular disease remains the most frequent cause of death, and cardiac rehabilitation programmes (CRP), typically consisting of supervised exercise, dietary, and health education, have been shown to reduce mortality by $20-25 \%$; these benefits are similar in magnitude to those of major cardiac drugs and surgery. ${ }^{2}$ Despite the established value of CRPs, participation rates are disappointingly low, with the participation of men typically limited to 25$31 \%$ of eligible patients, and the rate of participation of women being much lower at $11-20 \%$ of those eligible. $^{34}$ In consequence, researchers have attempted to identify sex differences and those factors that contribute to low participation rates. ${ }^{5}$ With respect to the low participation rate of women, there is consensus about a synergistic effect of lower fitness level, older age, and greater disease severity at first morbidity, as well as greater social isolation and depression in women. ${ }^{5-8}$

This review paper is not the only one to discuss relevant research on participation in CRPs; however, it is novel in that it summarises results in a succinct, quantitative form, represents the most comprehensive review to date, provides separate information about predictors of success
Heart 2005;91:10-14. doi: 10.1136/hrt.2004.045559

for the initial referral, for programme adherence once a structured programme is initiated, and separately focuses on adherence to lifestyle recommendations after CRP completion. Finally it provides sex specific results in the hope of contributing to closing the gender gap in CRP participation.

A large number of individual studies of varying quality and size have been reviewed previously and these narrative reviews have suggested the following as potentially critical variables: age, income, distance to the centre, and the beliefs and behaviour of the physician towards CRPs. ${ }^{6-8}$ The sometimes lengthy formats of these reviews typically provide broad qualitative coverage but do not quantify the strength of key findings. Previous reviews have not attended to variables that affect maintenance of healthy behaviours once the CRP is completed, and none have given differential weight to small versus large sample studies, although Todaro and colleagues recognise the influence of conducting studies with adequate statistical power. ${ }^{8}$

It is posited here that a comprehensive, transparent summary and identification of gaps in the literature is needed to maximise progress in the area of CRP participation. We are reporting results of predictors in three clusters that focus on referral to CRPs, adherence to CRPs once initiated, and those that target maintenance of healthy lifestyles once the structured CRP has been completed. It was predicted that factors which influence initial referral might differ from those affecting initial and/or long term adherence. Furthermore, it was intended to show sex differences that may require particular attention by CRP staff.

\section{METHODS}

A literature search was performed using four web search engines (PsycInfo, MedLine, Web of Science, and PubMed) with the keywords "cardiac rehabilitation" and "women", including articles published between 1990 and 2004 . Secondary references not identified with the initial search, were also followed up. From these sources, 98 articles met the initial criteria of being quantitative and testing either predictors of initial referral, immediate programme adherence, or adherence to long term recommended lifestyle changes. In order to prevent liberal biases arising from small sample studies, only studies with over 60 participants were included, of whom at least $20 \%$ or more were female. The rationale for focusing on recent studies was that CRPs have changed over time and programmes should be at least somewhat comparable in 
content. ${ }^{9}$ Furthermore, there is very little published about CRP participation before 1990 and women are rarely included in early studies.

This resulted in 32 pertinent articles describing data from 16804 patients, 5882 of whom were women. The resulting findings were organised into four categories of variables identified by previous writers. We included additional variables hypothesised as possibly playing a role in cardiac rehabilitation, namely physical distance to CRP, length of $\mathrm{CRP}$, and family obligations and role resumption. The four global categories of variables were: health systems, disease, psychological functioning, and demographics. Variables within each category were then studied across three stages of CRP: (1) the referral stage which involves the period of time before the onset of the CRP and revolves around the issue of whether the physician (or another health professional) refers the patient to a programme or not; (2) the participation stage which involves the patient's adherence (defined as percentage of sessions attended) to the CRP regardless of the length of time required to complete the programme; (3) the long term behavioural change stage which includes participation in the non-supervised phase of CRPs (that is, the maintenance of behaviour changes upon completion of the participation stage). Of the 32 articles included, 10 focused on referrals, 30 on participation, and six on long term behavioural change. These numbers do not add up to the total number of 32 articles as many articles examined more than one rehabilitation phase.

We decided against formal statistical meta-analysis because the field was not considered mature and cohesive enough to do so in a meaningful fashion; very few cells in the resulting matrix of three phases of rehabilitation multiplied by the 32 variables contained sufficient numbers of studies to allow meaningful effect size computations that would meet homogeneity of variance and fail safe number of participants' requirements. ${ }^{10}$ The current analytical approach uses a quantitative box score format that provides fewer details than a meta-analysis would offer but it has the advantage of fewer statistical requirements.

Findings are summarised in tables $1-4$ with referral, participation, and long term behavioural change forming the columns, and the categories health system (table 1), disease (table 2), psychological functioning (table 3), and demographics (table 4), and their respective clusters of potential predictor variables forming rows. The sample size cut off of $\mathrm{n}=60$ meant that we had $70 \%$ power to detect a two tailed medium sized effect $(r=0.3)$ and $95 \%$ power to detect a two tailed large effect size $(r=0.5)$.

All variables were defined as either a positive predictor, negative predictor, or not a predictor (for example, a positive predictor associated with high social support and referral meant that patients with high social support were more likely to be referred than those with low social support). Decisions about significant effect versus no effect were based on a probability cut off at $\mathrm{p}<0.05$ for the particular inferential statistic used (whether $\mathrm{r}$, multiple R, F, or t).

The first category of variables, health systems, begins with physician endorsement, which was defined as either a recommendation made to the patient and/or an outright, active referral to a CRP on the part of a general practitioner, internist, or cardiologist. Careful reading of the method sections of the studies suggested that there was variability in the intensity of the physician's recommendation, but frequently there was insufficient detail to allow breaking down the variable "physician endorsement" into more than one category, reflecting varying intensities of the recommendation and referral process. The resulting findings from the physician endorsement variable may therefore actually underestimate the importance of a strong, unambiguous recommendation of CRPs by physicians. ${ }^{3}$ Ease of physical access and transportation was defined as subjective perception of ease of travel whereas a long distance to CRP reflected the actual physical distance between the patient's home and the CRP. Length of CRP is defined as the duration of the CRP in weeks. Hypercholesterolaemia was defined as low density lipoprotein $\geqslant 100 \mathrm{mg} / \mathrm{dl}(\geqslant 2.6 \mathrm{mmol} / \mathrm{l})$ or total cholesterol $\geqslant 160 \mathrm{mg} / \mathrm{dl}(\geqslant 4.1 \mathrm{mmol} / \mathrm{l})$ with patients diagnosed with coronary artery disease. ${ }^{11}$ The general term of co-morbidity was applied when additional diseases were not specified. Disease severity is the progression of the cardiac illness or event according to the index of the diagnosing hospital.

The third category represented in table 3 is psychological functioning. Family obligations and role resumption, refers to the patient's perception of household duties which can be either domestic tasks or employment outside the home which provides for the family, and role resumption is commonly described as the return to employment or the resumption of domestic tasks. Self efficacy is defined by King and colleagues $^{12}$ as "a person's belief that he or she is able to engage in a particular behaviour".

The last category in table 4 is demographics which encompasses age, sex, minority, socioeconomic status, marital status, education, and insurance coverage.

\section{RESULTS \\ Referral}

One clear predictor of referral is the physician's endorsement and attitude towards effectiveness of CRP, with five out of five studies that examined physicians' endorsement and active referral supporting this conclusion..$^{43-16}$ Co-morbid patients were more likely to be referred to CRPs (two out of three studies examined). ${ }^{11}{ }^{17}$ Furthermore, patients with a primary diagnosis of either percutaneous transluminal coronary angioplasty, angina, coronary artery bypass grafting, or hypercholesterolaemia were referred more often to CRPs. ${ }^{4}{ }^{11}{ }^{16-18}$ Women and patients lacking medical insurance coverage were less likely to be referred (three out of four and two out of three studies examined, respectively). ${ }^{14}{ }^{17} 19-21$

Table 1 Health systems

\begin{tabular}{|c|c|c|c|c|c|c|c|c|c|}
\hline & \multicolumn{3}{|l|}{ Referral } & \multicolumn{3}{|c|}{ Participation } & \multicolumn{3}{|c|}{ Long term behavioural change } \\
\hline & $\begin{array}{l}\text { Positive } \\
\text { predictor }\end{array}$ & $\begin{array}{l}\text { Negative } \\
\text { predictor }\end{array}$ & $\begin{array}{l}\text { Not a } \\
\text { predictor }\end{array}$ & $\begin{array}{l}\text { Positive } \\
\text { predictor }\end{array}$ & $\begin{array}{l}\text { Negative } \\
\text { predictor }\end{array}$ & $\begin{array}{l}\text { Not a } \\
\text { predictor }\end{array}$ & $\begin{array}{l}\text { Positive } \\
\text { predictor }\end{array}$ & $\begin{array}{l}\text { Negative } \\
\text { predictor }\end{array}$ & $\begin{array}{l}\text { Not a } \\
\text { predictor }\end{array}$ \\
\hline Physician's endorsement & 5 & 0 & 0 & 12 & 0 & 0 & 0 & 0 & 0 \\
\hline Male physician & 1 & 0 & 0 & 0 & 0 & 0 & 0 & 0 & 0 \\
\hline Ease of physical access & 0 & 0 & 1 & 9 & 2 & 1 & & & \\
\hline and transportation & & & & & & & NA & NA & NA \\
\hline Long distance to CRP & 0 & 1 & 0 & 0 & 5 & 0 & NA & NA & NA \\
\hline Length of CRP & 0 & 0 & 0 & 0 & 1 & 0 & 1 & 0 & 0 \\
\hline
\end{tabular}


Table 2 Disease

\begin{tabular}{|c|c|c|c|c|c|c|c|c|c|}
\hline & \multicolumn{3}{|l|}{ Referral } & \multicolumn{3}{|c|}{ Participation } & \multicolumn{3}{|c|}{ Long term behavioural change } \\
\hline & $\begin{array}{l}\text { Positive } \\
\text { predictor }\end{array}$ & $\begin{array}{l}\text { Negative } \\
\text { predictor }\end{array}$ & $\begin{array}{l}\text { Not a } \\
\text { predictor }\end{array}$ & $\begin{array}{l}\text { Positive } \\
\text { predictor }\end{array}$ & $\begin{array}{l}\text { Negative } \\
\text { predictor }\end{array}$ & $\begin{array}{l}\text { Not a } \\
\text { predictor }\end{array}$ & $\begin{array}{l}\text { Positive } \\
\text { predictor }\end{array}$ & $\begin{array}{l}\text { Negative } \\
\text { predictor }\end{array}$ & $\begin{array}{l}\text { Not a } \\
\text { predictor }\end{array}$ \\
\hline \multicolumn{10}{|l|}{ Primary diagnosis } \\
\hline $\mathrm{MI}$ & 1 & 1 & 1 & 1 & 1 & 8 & 1 & 0 & 2 \\
\hline PTCA & 2 & 0 & 0 & 3 & 1 & 1 & 1 & 0 & 2 \\
\hline Angina & 2 & 0 & 0 & 1 & 2 & 1 & 0 & 0 & $\overline{1}$ \\
\hline CABG & 2 & 1 & 0 & 2 & 0 & 1 & 0 & 0 & 0 \\
\hline Hypercholesterolaemia & 2 & 1 & 0 & 3 & 0 & 1 & 0 & 0 & 0 \\
\hline Co-morbidity & 2 & 1 & 0 & 3 & 3 & 2 & 0 & 1 & 1 \\
\hline Diabetes & 1 & 0 & 1 & 2 & 1 & 0 & 0 & 0 & 0 \\
\hline Arthritis & 0 & 0 & 0 & 0 & 1 & 0 & 0 & 0 & 1 \\
\hline Hypertension & 1 & 0 & 0 & 2 & 1 & 4 & 0 & 0 & 1 \\
\hline Disease severity & 0 & 0 & 1 & $\overline{1}$ & 3 & 2 & 0 & 1 & 2 \\
\hline Smoking & 0 & 0 & 2 & 1 & 3 & 8 & 0 & 1 & 2 \\
\hline High exercise capacity & 0 & 0 & 0 & 1 & 1 & 0 & 0 & 0 & 0 \\
\hline Low BMI & 1 & 0 & 0 & 2 & 1 & 3 & 0 & 0 & 2 \\
\hline
\end{tabular}

BMI, body mass index; CABG, coronary artery bypass surgery; MI, myocardial infarction; PTCA, percutaneous transluminal coronary angioplasty.

\section{Participation}

The strongest predictors of ongoing participation were physician's endorsement (all 12 studies examined), ${ }^{411} 13$ $14162022-27$ ease of physical access, and transportation (nine out of 12 studies), ${ }^{3} 14182024-28$ and high self-efficacy (seven out of eight studies). ${ }^{12} 19242629-31$ The variables high social support (three out of five studies), ${ }^{25} 2730$ high socioeconomic status (three out of five studies), ${ }^{3} 3032$ and high education (seven out of 11 studies) 3131920262732 were also consistent positive predictors of participation. Patients with diabetes participated more often than patients with other co-morbid diseases (two out of three studies). ${ }^{11}{ }^{16}$ Within primary diagnosis, two variables were found to be positive predictors of participation: hypercholesterolaemia (three out of four studies) and percutaneous transluminal coronary angioplasty (three out of five studies). ${ }^{11} 131617$

The strongest predictors of non-participation were long distance to CRP (all five studies examined) 24252730 and lack of insurance coverage (five out of six studies examined). ${ }^{1426} 273033$ Women were also less likely to participate (13 out of 23 studies). ${ }^{411-14161922} 23313334$ Within psychological functioning, family obligations and role resumption were found to be negative predictors four times out of five. ${ }^{12} 182527$ Notably, participation rates were not affected by primary diagnosis of myocardial infarction (eight out of 10 studies) $11232831-35$ or smoking (eight out of 12 studies). ${ }^{1123242628323436}$

\section{Long term behavioural change}

With only six pertinent articles, no clear positive or negative predictor variables were found; neither disease severity (two out of three studies), primary diagnosis of myocardial infarction (two out of three studies) and percutaneous transluminal coronary angioplasty (two out of three studies), nor employed status (two out of three studies) were found to be predictors. ${ }^{34} 37$

\section{Significant sex differences}

The probability of referral and participation in CRPs was lower for women in over half of all the studies examined (three out of four and 13 out of 23 , respectively). ${ }^{3}{ }^{11-14}$ 16171923 31-34 Married female patients participated less often than did married male patients. Old age, obesity, disease severity, the presence of disease co-morbidity, as well as family obligations and role resumptions, reduced adherence and these characteristics are particularly descriptive of female cardiac patients.

\section{DISCUSSION}

Whereas numerous predictor variables were found within the referral and participation categories, no positive predictor variables were identified that were relevant to all three phases of cardiac rehabilitation. Factors that influenced referral differed from those affecting CRP participation and/ or long term behaviour change, indicating that each phase of CRP must be examined individually to maximise participants' involvement throughout their recovery. Physician's endorsement of CRPs was found to be the principle predictor of referral and participation, and the presence of a primary diagnosis of percutaneous transluminal coronary angioplasty, coronary artery bypass grafting, and hypercholesterolaemia were also found to be strong predictors in both categories.

Although the sex of the physician was only studied once, with a sample of $n=203$ patients, it was striking that male

Table 3 Psychological functioning

\begin{tabular}{|c|c|c|c|c|c|c|c|c|c|}
\hline & \multicolumn{3}{|l|}{ Referral } & \multicolumn{3}{|c|}{ Participation } & \multicolumn{3}{|c|}{ Long term behavioural change } \\
\hline & $\begin{array}{l}\text { Positive } \\
\text { predictor }\end{array}$ & $\begin{array}{l}\text { Negative } \\
\text { predictor }\end{array}$ & $\begin{array}{l}\text { Not a } \\
\text { predictor }\end{array}$ & $\begin{array}{l}\text { Positive } \\
\text { predictor }\end{array}$ & $\begin{array}{l}\text { Negative } \\
\text { predictor }\end{array}$ & $\begin{array}{l}\text { Not a } \\
\text { predictor }\end{array}$ & $\begin{array}{l}\text { Positive } \\
\text { predictor }\end{array}$ & $\begin{array}{l}\text { Negative } \\
\text { predictor }\end{array}$ & $\begin{array}{l}\text { Not a } \\
\text { predictor }\end{array}$ \\
\hline Depression & 0 & 0 & 2 & 3 & 1 & 5 & 0 & 0 & 2 \\
\hline Anxiety disorder & 1 & 0 & 0 & 3 & 2 & 1 & 0 & 0 & 2 \\
\hline $\begin{array}{l}\text { Family obligations } \\
\text { and role resumption }\end{array}$ & 0 & 0 & 0 & 0 & 4 & 1 & 0 & 0 & 1 \\
\hline High social support & 1 & 0 & 1 & 3 & 0 & 2 & 1 & 0 & 0 \\
\hline Hostility or anger & 0 & 0 & 0 & 0 & 0 & 0 & 0 & 0 & 1 \\
\hline High self efficacy & 0 & 0 & 0 & 7 & 0 & 1 & 1 & 0 & 1 \\
\hline
\end{tabular}


Table 4 Demographics

\begin{tabular}{|c|c|c|c|c|c|c|c|c|c|}
\hline & \multicolumn{3}{|l|}{ Referral } & \multicolumn{3}{|c|}{ Participation } & \multicolumn{3}{|c|}{ Long term behavioural change } \\
\hline & $\begin{array}{l}\text { Positive } \\
\text { predictor }\end{array}$ & $\begin{array}{l}\text { Negative } \\
\text { predictor }\end{array}$ & $\begin{array}{l}\text { Not a } \\
\text { predictor }\end{array}$ & $\begin{array}{l}\text { Positive } \\
\text { predictor }\end{array}$ & $\begin{array}{l}\text { Negative } \\
\text { predictor }\end{array}$ & $\begin{array}{l}\text { Not a } \\
\text { predictor }\end{array}$ & $\begin{array}{l}\text { Positive } \\
\text { predictor }\end{array}$ & $\begin{array}{l}\text { Negative } \\
\text { predictor }\end{array}$ & $\begin{array}{l}\text { Not a } \\
\text { predictor }\end{array}$ \\
\hline Old age & 3 & 3 & 2 & 3 & 10 & 9 & 1 & 0 & 2 \\
\hline Female sex & 0 & 3 & 1 & 0 & 13 & 10 & 0 & 1 & 2 \\
\hline Racial minority & 0 & 1 & 1 & 1 & 3 & 3 & 0 & 0 & 1 \\
\hline High SES & 0 & 0 & 0 & 3 & 1 & 1 & 0 & 0 & 1 \\
\hline Married & 1 & 0 & 1 & 6 & 1 & 4 & 0 & 0 & 1 \\
\hline High education & 0 & 0 & 0 & 7 & 0 & 4 & 0 & 0 & 2 \\
\hline Employed & 0 & 0 & 1 & 4 & 1 & 4 & 1 & 0 & 2 \\
\hline Lack of insurance coverage & 0 & 2 & 1 & 0 & 5 & 1 & 0 & 1 & 0 \\
\hline
\end{tabular}

physicians $(n=21)$ were 13 times more likely to refer patients to CRPs than female physicians $(n=4) .{ }^{21}$

Several variables of interest had not been adequately addressed previously; the length of CRP reduced participation but enhanced long term behavioural change, however this was examined in only one of the 32 articles examined. ${ }^{34}$ Filip and colleagues found that preferences for specific programme lengths and types differed significantly by age; participants over 65 years of age preferred longer programmes than younger participants, and older participants preferred home based programmes. ${ }^{38}$ Exercise capacity was examined in only two of the 32 articles, although previous research leads us to believe that women have as much to gain from regular exercise as do men. ${ }^{19}{ }^{39}$ Family obligations and role resumption reduced participation rates but was not a predictor of long term behavioural change. This is consistent with previous findings showing that women experience guilt when a family member must help with a household task when the women themselves are recovering from a cardiac event. ${ }^{40}$ The low number of pertinent studies and differing results suggest a need for further investigation.

\section{Sex differences}

Women were referred less often and adhered less often to CRPs and this is likely to be because of the presence of a cluster of predictors that are particularly prevalent in women, namely, increased age, greater co-morbidity, higher depression, lower initial exercise capacity, and less available social support. ${ }^{4} 3841$ Given that many variables in this predictor cluster are not modifiable, the ones that can be modified should receive particular attention and aggressive intervention (that is, physician endorsement, instruction in the efficacy of programmes, tailoring to individual preferences and needs, and paying attention to the emotional needs of women). ${ }^{42}$ For example, older women are generally inexperienced with high intensity exercise, a component of most phase II CRPs, and this affects their participation and adherence to these programmes. ${ }^{43}$ Older women are also more likely to be widowed than similarly aged men, ${ }^{19}$ or have an elderly spouse to whom they are the primary caregiver. ${ }^{4} 7$ Elderly women are also less likely to drive and are therefore more often reliant on others or public transportation; this reliance impedes attendance at CRPs. ${ }^{14}$ Women want feedback and encouragement from professionals, and although men also reported the importance of feedback and encouragement, they were much more goal orientated than women. ${ }^{44}$ Depression in cardiac patients can lead to an increased risk of morbidity and mortality and women are twice as likely to suffer from depression as men. ${ }^{6}$ Despite these facts, there is very little known about the impact of depression on the participation of female cardiac patients on CRPs, with one study stating that depressed patients are twice as likely to drop out,,$^{35}$ while in another, depression in women did not affect attendance. ${ }^{19}$

\section{Clinical implications}

Many obstacles to participation cannot be changed (age, initial disease severity, diagnosis, sex, and educational attainment) which makes it imperative that those factors that are open to modification are also aggressively pursued, beginning with efforts to maximise referral rates. Here, the treating physician and other professionals involved in acute cardiac care play a pivotal role given that aggressive referrals not only get patients to the CRPs but, as our data suggest, also lay the groundwork for better adherence. In the method section, we acknowledged that the intensity of the physician's endorsement was difficult to assess in the articles reviewed, although there is powerful evidence of a gradient effect as shown by Ades and colleagues. ${ }^{3}$ When patients rated the strength of the endorsement as less than four on a five point scale, the resulting CRP participation rate was $1.8 \%$, whereas a strong endorsement (rated four or five by the patient on the same five point scale) resulted in a participation rate of $66 \%$. We therefore urge that patients be informed about cardiac rehabilitation while still in the hospital for acute care, that physicians endorse CRPs in the strongest possible terms, and that an active referral to CRP is made for the patient, such that upon leaving the hospital an appointment with a CRP intake staff member is already scheduled. The referring professional can educate the patient about the benefits of CRPs and point out that co-morbid conditions, disease severity, depression, or low exercise capacity, are not obstacles to CRP benefits.

The first contact person in the chain from acute care hospital to CRP should ask the patient what his/her perceived obstacles are and what type of intervention the patient prefers. Qualitative and quantitative research has indicated that a mismatch of expectations and programme realities makes patients vote with their feet and simply stay away. ${ }^{72} 18384445$ Older women especially may express a dislike of mixed sex exercise groups, have low initial exercise capacity, and worry about inability to maintain household obligations and their role as caregiver. Younger women are also staying away from CRP because of the misperception that rehabilitation is only for older adults. ${ }^{45}$ Many participants, particularly women, resent the prescriptive, highly structured exercise component and feel that their emotional needs are not met by typical CRPs. ${ }^{46}$ Similarly, racial minorities are less likely to be referred and are much less likely to participate. While race, of course, is not modifiable it can be seen as a proxy for language difficulties and cultural alienation, which are open to modification. In the USA, lack of insurance coverage may not be easily resolved at the level of the individual patient; however, insurance companies and health care professionals can jointly work out a case for cost 
benefit of CRPs, such that future patient cohorts do not have to overcome this systemic obstacle. This has been successfully done by the Mutual of Omaha and Ornish's group ${ }^{47}$ and can serve as a model for other insurers.

\section{ACKNOWLEDGEMENTS}

We would like to acknowledge Dr Scott Lear for his critical review of the article, as well as Martine Habra and Erin Putterman for editing. Special thanks go to the Heart and Stroke Foundation, and the Canadian Institute for Health Research for providing operating grants to the fourth author.

\section{Authors' affiliations}

L Jackson, J Leclerc, Y Erskine, W Linden, University of British Columbia, Vancouver, British Columbia, Canada

\section{REFERENCES}

1 Lau J, Antman EM, Jimenez-Silva J, et al. Cumulative meta-analysis of therapeutic trials for myocardial infarction. N Engl J Med 2002;327:248-54

2 Wenger N, Froelicher E, Smith L, et al. Cardiac rehabilitation as secondary prevention.(Clinical Practice Guideline No. 17). Rockville, Maryland: US Department of Health and Human Services, Public Health Service, Agency for Health Care Policy and Research and the National Heart, Lung, and Blood Institute, 1995.

3 Ades PA, Walmann ML, Polk DM, et al. Referral patterns and exercise response in the rehabilitation of female coronary patients aged $\geqslant 62$ years. Am J Cardiol 1992:69:1422-5.

4 *Barber K, Stommel M, Kroll J, et al. Cardiac rehabilitation for community based patients with myocardial infarction: Factors predicting discharge recommendation and participation. J Clin Epidemiol 2001;54:1025-30.

5 Abbey SE, Stewart DE. Gender and psychosomatic aspects of ischemic heart disease. J Psychosom Res 2000;48:417-23.

6 Benz Scott LA, Ben-or K, Allen JK. Why are women missing form outpatient cardiac rehabilitation programmes? A review of multilevel factors affecting referral, enrolment, and completion. J Womens Health 2002;11:773-91.

7 Cooper AF, Jackson G, Weinman J, et al. Factors associated with cardiac rehabilitation attendance: a systematic review of the literature. Clin Rehabil 2002;16:541-52.

8 Todaro JF, Shen B, Niaura R, et al. Do men and women achieve similar benefits from cardiac rehabilitation? J Cardiopulm Rehabil 2004;24:45-51.

9 Linden W. Psychological treatments in cardiac rehabilitation: review of rationales and outcomes. J Psychosom Res 2000;48:443-54.

10 Rosenthal R, Rubin DB. Statistical analysis: summarizing evidence vs. establishing facts. Psychol Bull 1985;97:527-9.

11 *Richardson LA, Buckenmeyer PJ, Bauman BD, et al. Contemporary cardiac rehabilitation: patient characteristics and temporal trends over the past decade. J Cardiopulm Rehabil 2000;20:57-64.

12 King KM, Humen DP, Smith HL, et al. Psychosocial components of cardiac recovery and rehabilitation attendance. Heart 2001;85:290-8.

13 *Evenson KR, Rosamond WD, Luepker RV. Predictors of outpatient cardiac rehabilitation utilization: the Minnesota heart survey registry. J Cardiopulm Rehabil 1998;18:192-8.

14 *Halm M, Penque S, Doll N, et al. Women and cardiac rehabilitation: referral and compliance patterns. J Cardiovasc Nurs 1999;13:83-92.

15 *Caulin-Glaser T, Blum M, Schmeizl R, et al. Gender differences in referral to cardiac rehabilitation programmes after revascularization. J Cardiopulm Rehabil 2001;21:24-30

16 *Thomas RJ, Houston Miller N, Lamendola C, et al. National survey on gender differences in cardiac rehabilitation programmes: patient characteristics and enrolment patterns. J Cardiopulm Rehabil 1996;16:402-412.

17 *Bittner V, Sanderson B, Breland J, et al. Referral patterns to a universitybased cardiac rehabilitation programme. Am J Cardiol 1999;83:252-5.

18 *Plach SK. Women and cardiac rehabilitation after heart surgery: patterns of referral and adherence. Rehabil Nurs 2002;27:104-9.

19 *Grace SL, Abbey SE, Shnek ZM. Cardiac rehabilitation II: referral and participation. Gen Hosp Psychiatry 2002;24:127-34.

$20{ }^{*}$ Missik E. Women and cardiac rehabilitation: accessibility issues and policy recommendations. Rehabil Nurs 2001;26(4):141-7.

21 *Stiller JJ, Holt MM. Factors influencing referral of cardiac patients for cardiac rehabilitation. Rehabil Nurs 2004;29(1):18-23.

22 *Ades PA, Waldman ML, McCann WJ, et al. Predictors of cardiac rehabilitation in older coronary patients. Arch Intern Med 1992;152:1033-5.

23 *Blackburn GG, Foody J, Sprecher DL, et al. Cardiac rehabilitation participation patterns in a large, tertiary care centre: evidence for selection bias. J Cardiopulm Rehabil 2000;20:189-95.
24 *King KM, Humen DP, Smith $\mathrm{HL}$, et al. Predicting and explaining cardiac rehabilitation attendance. Can J Cardiol 2001;17:291-6.

25 *Lieberman L, Meana M, Stewart D. Cardiac rehabilitation: gender differences in factors influencing participation. J Womens Health 1998:7:717-23.

26 *McHugh Schuster P, Wright C, Tomich P. Gender differences in the outcomes of participants in home programmes compared to those in structured cardiac rehabilitation programmes. Rehabil Nurs 1995;20:93-101.

$27 *$ Yates BC, Braklow-Whitton JL, Agrawal S. Outcomes of cardiac rehabilitation participants and non-participants in a rural area. Rehabil Nurs 2003;28:57-63.

28 *Cooper A, Lloyd G, Weinman J, et al. Why patients do not attend cardiac rehabilitation: role of intentions and illness beliefs. Heart 1999;82:234-6.

29 Blanchard CM, Rodgers WM, Courneya KS, et al. Does barrier efficacy mediate the gender-exercise adherence relationship during phase II cardiac rehabilitation? Rehabil Psychol 2002;47:106-20.

30 Johnson JE, Weinert C, Richardson JK. Rural residents use of cardiac rehabilitation programmes. Public Health Nurs 2001;15(4):288-96.

31 *McHugh Schuster P, Waldron J. Gender differences in cardiac rehabilitation patients. Rehabil Nurs 1991;16(5):248-53.

32 *Harlan WR, Sandler SA, Lee KL, et al. Importance of baseline functional and socioeconomic factors for participation in cardiac rehabilitation. Am J Cardiol 1995;76:36-9.

33 *Oldridge NB, Ragowski B, Gottlieb M. Use of outpatient cardiac rehabilitation services. J Cardiopulm Rehabil 1992;12:25-31.

34 *Bock BC, Carmona-Barros RE, Esler JE, et al. Programme participation and physical activity maintenance after cardiac rehabilitation. Behav Modif 2003;27:37-53.

35 *Turner SC, Hugh JN, Evans JA, et al. Patient characteristics and outcomes of cardiac rehabilitation. J Cardiopulm Rehabil 2002;22:253-60.

$36{ }^{*}$ Whitmarsh A, Koutantii M, Sidell K. Illness perceptions, mood and coping in predicting attendance at cardiac rehabiliation. Br J Health Psychol 2003;8:209-21.

37 *Moore SM, Dolansky MA, Ruland CM, et al. Predictors of women's exercise maintenance after cardiac rehabilitation. J Cardiopulm Rehabil 2003;23:40-9

38 Filip J, McGillen C, Mosca L. Patient preferences for cardiac rehabilitation and desired programme elements. J Cardiopulm Rehabil 1999;19:339-43.

39 O'Farrel P, Murray J, Huston P, et al. Sex differences in cardiac rehabilitation. Can J Cardiol 2000;16:319-25.

40 Benson G, Arthur HM, Rideout E. Women and heart attack: a study of women's experiences. Can J Cardiovasc Nurs 1997;8(3):16-23.

41 *Jones CA, Valle M, Manring S. Using survival analysis to explore female cardiac rehabilitation programme adherence. Appl Nurs Res 2001;14:179-86.

42 Moore SM. Women's views of cardiac rehabilitation programmes. J Cardiopulm Rehabil 1996;16:123-9.

43 Hassmen P, Ceci R, Backman, L. Exercise for older women: A training method and its influences on physical and cognitive performance. Eur J Appl Physiol Occup Physiol 1992;64:460-6

44 Moore SM, Kramer FM. Women's and men's preferences for cardiac rehabilitation programme features. J Cardiopulm Rehabil 1996;16:163-8.

45 McSweeney JC, Crane PB. An act of courage: women's decision-making processes regarding outpatient cardiac rehabilitation attendance. Cardiac Rehabil 2001;26:132-40.

46 *Cossette S, Frasure-Smith N, Lesperance F. Nursing approaches to reducing psychological distress in men and women recovering from myocardial infarction. Int Nurs Stud 2002;39:479-94.

47 Koertge J, Weidner G, Elliott-Eller M, et al. Improvement in medical risk factors and quality of life in women and men with coronary artery disease in the multicentre lifestyle demonstration project. Am J Cardio 2003;91:1316-22

48 *Blanchard CM, Rodgers WM, Courneya KS, et al. Self-efficacy and mood in cardiac rehabilitation: should gender be considered? Behav Med 2002; 27: 149-60.

49 *Cannistra LB, Balady GJ, O'Malley CJ, et al. Comparison of the clinical profile and outcome of women and men in cardic rehabilitation. Am J Cardiol 1992;69:1272-9

50 *Cannistra LB, O'Malley CJ, Balady GJ. Comparison of outcome of cardiac rehabilitation in black women and white women. Am J Cardiol 1995;75:890-3.

51 *Farley RL, Wade TD, Birchmore L. Factors influencing attendance at cardiac rehabilitation among coronary heart disease patients. Eur J Cardiovasc Nurs 2003;2:205-12.

52 *King KM, Koon KT. Cardiac rehabilitation referral and attendance: not one and the same. Rehabil Nurs 1998;23:46-251.

53 *Sin M, Sanderson B, Weaver M, et al. Personal characteristics, health status, physical activity, and quality of life in cardiac rehabilitation participants. Int J Nurs Stud 2004:41:173-81.

*Articles in reference list used to calculate data in tables 